\title{
Acné juvenil, tratamiento por el pediatra. ¿Cuándo enviar al especialista?
}

\section{Acne vulgaris, management by the pediatrician. When to send to the specialist?}

Gibert Maza-Ramos, ${ }^{1}$ Eduardo Liquidano-Pérez, ${ }^{2}$ Marimar Saéz-de-Ocariz, ${ }^{1}$ Luz Orozco-Covarrubias ${ }^{1}$

\section{INTRODUCCIÓN}

El acné juvenil o acné vulgar es una enfermedad inflamatoria crónica que afecta a la unidad pilosebácea. La producción de sebo por las glándulas sebáceas, secundaria al estímulo hormonal, condiciona un proceso obstructivo del conducto pilosebáceo por retención de sebo y células anormales seguido de un proceso inflamatorio. Generalmente es de inicio lento, de evolución prolongada, con remisiones parciales y brotes agudos.

\section{EPIDEMIOLOGÍA}

El acné es la octava enfermedad más prevalente en el mundo, ${ }^{1}$ una revisión sistemática demuestra que alrededor de $85 \%$ de la población entre 12 y 24 años tiene algún grado de acné; y entre 15 y $20 \%$ de los pacientes entre 15 y 17 años tienen afectación moderada a grave. ${ }^{2}$ En el Centro Dermatológico Dr. Ladislao de la Pascua (México) es la primera causa de consulta de adolescentes, con una incidencia anual de 120 por cada 1,000 pacientes de primera vez. ${ }^{3}$

En el servicio de Dermatología del Instituto Nacional de Pediatría el acné es una de las 10 dermatosis más frecuentes y es la dermatosis número uno en los adolescentes..$^{4-5} \mathrm{Su}$ aparición es más precoz en el sexo femenino, inicia alrededor de los 10 años en mujeres y alrededor de los 12 años en varones. El 70\% de los casos tienen antecedente familiar de acné. ${ }^{6}$

Puesto que el pediatra es el especialista responsable de la salud de niños y adolescentes y las enfermedades de la piel representan entre 6 y $24 \%$ de la consulta pediátrica, el conocimiento del acné por parte del pediatra es fundamental para el tratamiento inicial adecuado.

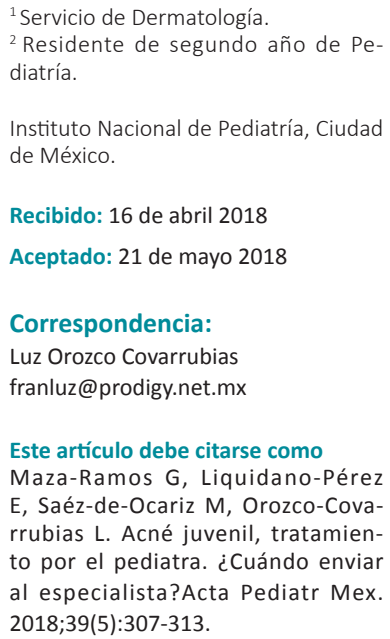

${ }^{1}$ Servicio de Dermatología.

${ }^{2}$ Residente de segundo año de Pediatría.

Instituto Nacional de Pediatría, Ciudad de México.

Recibido: 16 de abril 2018

Aceptado: 21 de mayo 2018

Correspondencia:

Luz Orozco Covarrubias

franluz@prodigy.net.mx

Este artículo debe citarse como Maza-Ramos G, Liquidano-Pérez $E$, Saéz-de-Ocariz M, Orozco-Covarrubias L. Acné juvenil, tratamiento por el pediatra. ¿Cuándo enviar al especialista?Acta Pediatr Mex. 2018;39(5):307-313. 


\section{ETIOPATOGENIA}

Los cuatro principales factores patogénicos del acné son: hiperplasia de glándulas sebáceas y aumento en la producción de sebo, alteración en la queratinización folicular, colonización por Propioniibacterium acnes e inflamación. La interacción entre estos factores y el acné se esquematiza en la Figura 1.

Los factores de riesgo particularmente relacionados con acné moderado a severo incluyen: antecedente familiar positivo de acné, índice de masa corporal mayor de $23 \mathrm{~kg} / \mathrm{m}^{2}$ sobre todo en varones y el consumo de leche (en particular descremada) más de tres veces por semana..$^{7-8}$

Otros factores participantes en la patogénesis del acné carecen de fundamento científico o la evi- dencia es controvertida; el estrés, por ejemplo, mientras que algunos estudios lo apoyan como factor exacerbante del acné; otros no han demostrado relación entre la intensidad del estrés y la gravedad del acné. ${ }^{9}$

\section{MANIFESTACIONES CLÍNICAS}

El acné juvenil afecta las áreas de la piel con abundantes glándulas sebáceas que reaccionan al estímulo hormonal e incluyen: cara y tórax superior, anterior y posterior, excepto los hombros que rara vez son afectados.

Las lesiones elementales del acné se dividen en tres grupos, que pueden o no concurrir secuencialmente: no inflamatorias, inflamatorias y residuales (Figura 2). La piel subyacente es, por lo general, oleosa.

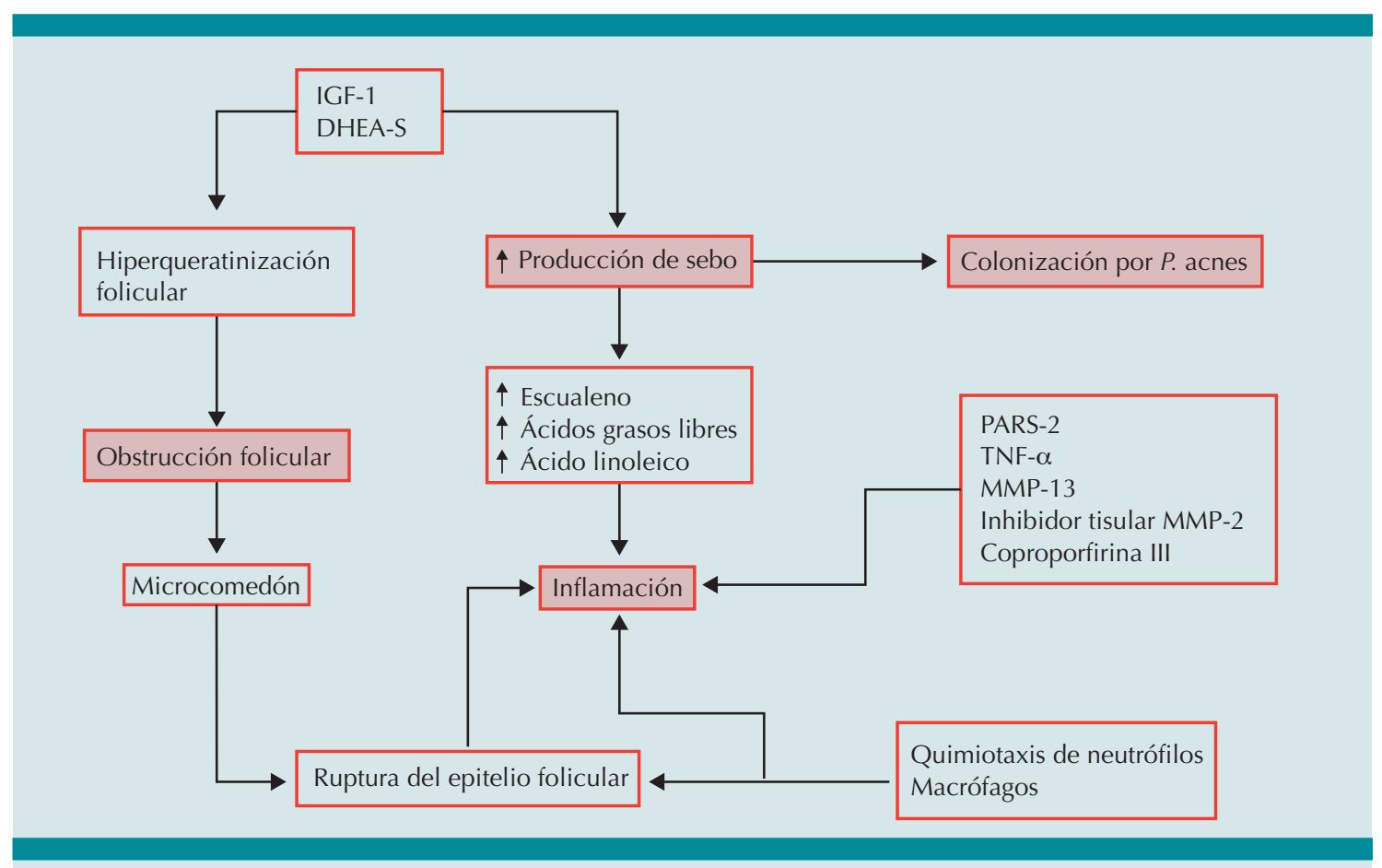

Figura 1. Fisiopatología del acné.

IGF: factor de crecimiento análogo a la insulina; DHEA-S: sulfato de dehidroepiandrosterona; PARS: receptor activado por proteinasa; TNF- $\alpha$ : Factor de necrosis tumoral alfa; MMP: metaloproteinasa de la matriz 


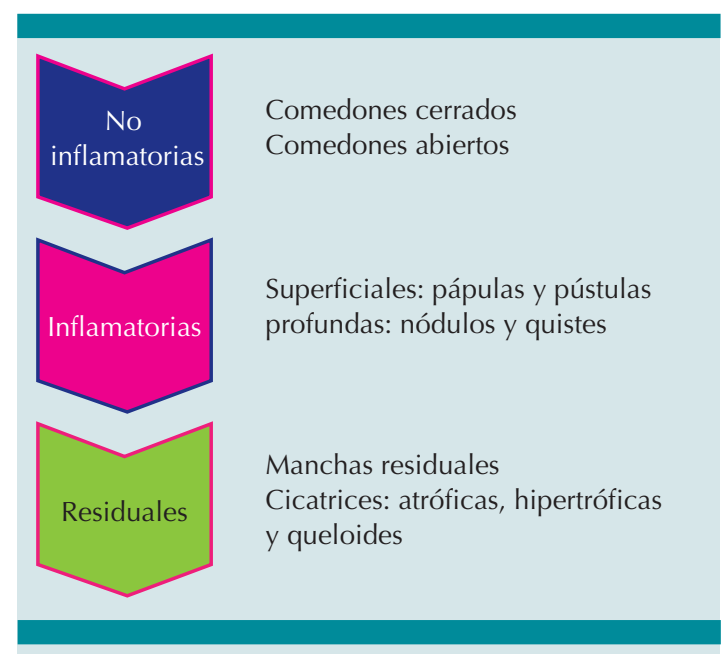

Figura 2. Clasificación de las lesiones de acné.

Lesiones no inflamatorias: la lesión elemental característica del acné es el comedón, puede ser abierto o cerrado. Los comedones cerrados son levantamientos milimétricos del color de la piel o blanquecinos sin orificio visible. Los comedones abiertos (conocidos coloquialmente como espinillas) se caracterizan por una apertura central, con acumulación de un material negruzco que corresponde a queratina y melanina oxidada.

Lesiones inflamatorias: las pápulas son levantamientos sólidos eritematosos, de tamaño variable (1 a 4 mm); las pústulas son levantamientos de contenido purulento superficial o profundo de tamaño similar a las pápulas, desaparecen en días (superficiales) o en 2 a 3 semanas (profundas). Al desaparecer no dejan cicatriz, su manipulación puede condicionar lo contrario. Los nódulos o quistes (pseudoquistes) son colecciones de sebo, queratina y detritus celulares profundos (dermis), de $5 \mathrm{~mm}$ o más, desaparecen en semanas (más de 4) y dejan cicatriz. Pueden confluir y formar trayectos sinuosos en la dermis profunda o en el tejido celular subcutáneo.

Lesiones residuales o secuelas: pueden ser transitorias o permanentes. Las manchas eritematosas son transitorias; sin embargo, las manchas hi- perpigmentadas pueden no serlo. Las cicatrices pueden ser: atróficas (deprimidas) puntiformes o variceliformes; o hipertróficas (salientes). Las cicatrices queloides por lo general afectan al tórax.

Existen diferentes clasificaciones del acné pero la más útil para fines de tratamiento es la que se basa en las lesiones dominantes: acné no inflamatorio (comedónico) y acné inflamatorio que puede ser leve (comedones y menos de 10 lesiones inflamatorias, Figura 3), moderado (comedones, pápulas y pústulas, Figura 4) y severo

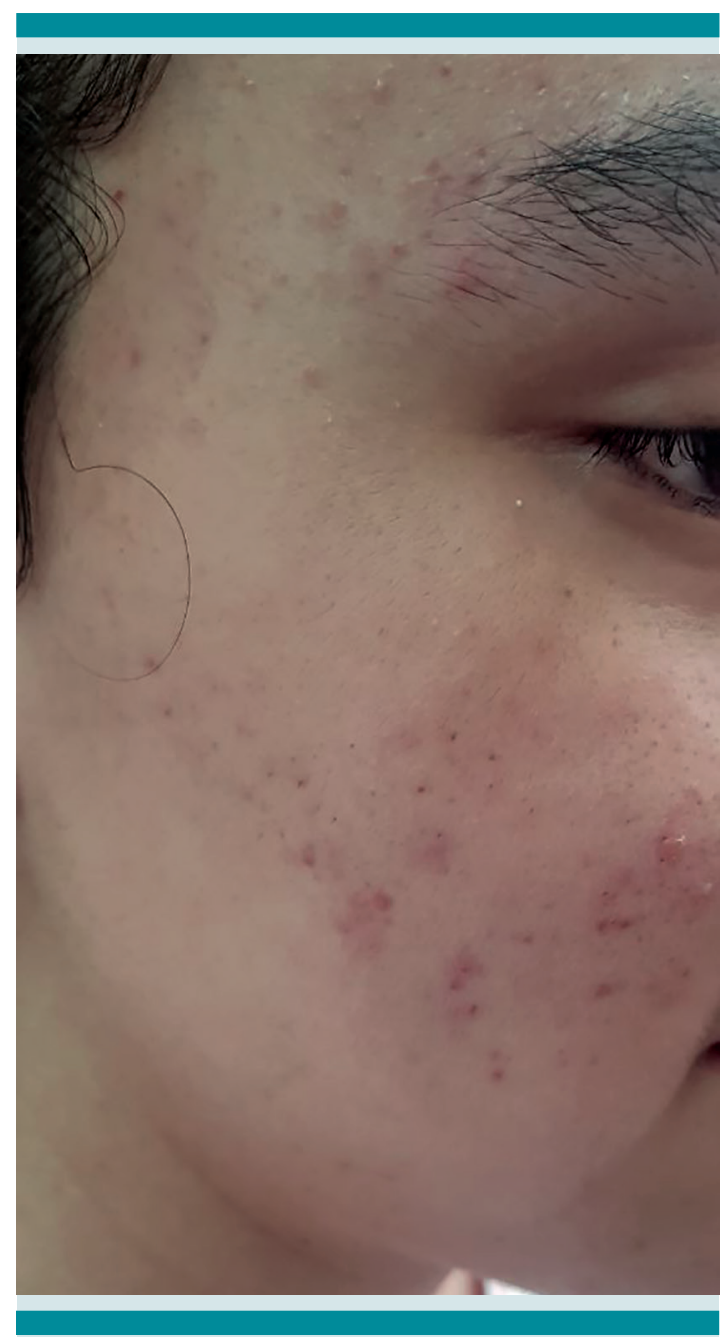

Figura 3. Acné inflamatorio leve. Múltiples comedones y menos de 10 pápulas y pústulas. 
(comedones, pápulas, pústulas, nódulos, quistes con o sin trayectos sinuosos, Figura 5).

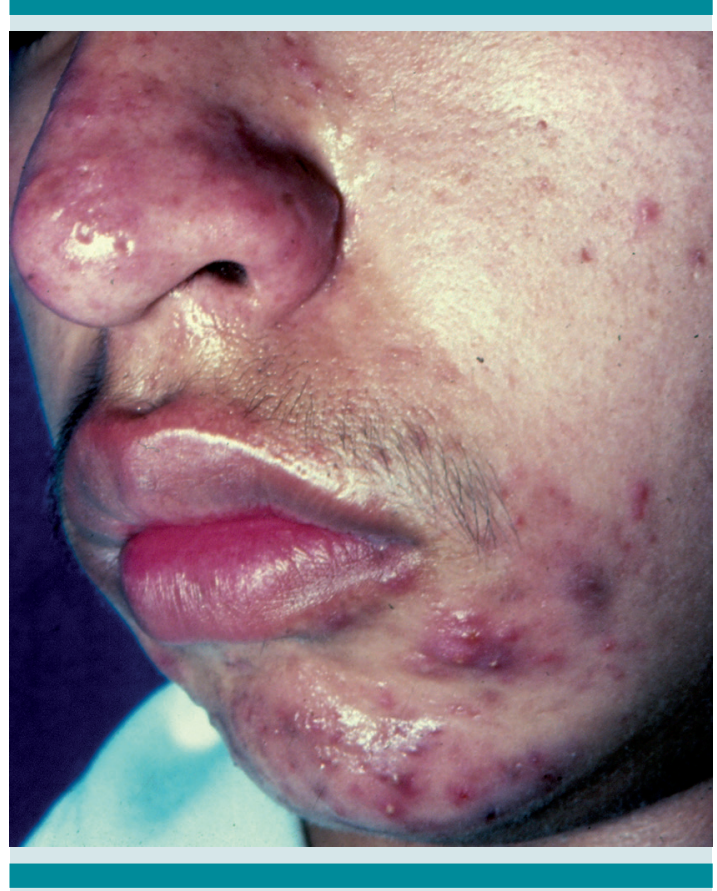

Figura 4. Acné moderado. Comedones y múltiples pápulas y pústulas.

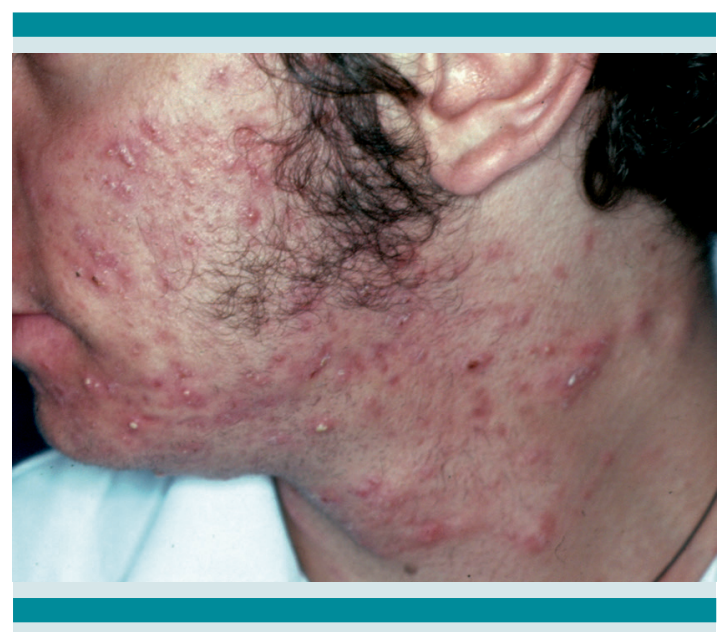

Figura 5. Acné severo. Pápulas, pústulas y nódulos.

\section{EVALUACIÓN DIAGNÓSTICA}

El diagnóstico del acné juvenil se basa en el examen clínico, la existencia de comedones (abiertos o cerrados) con o sin lesiones inflamatorias en las áreas habituales.

El acné puede ser el primer signo de la pubertad como resultado de la maduración normal testicular-ovárica por lo que el abordaje clínico (historia clínica y exploración física completa) suele ser suficiente. Si hay signos de hiperandrogenismo se requiere evaluación endocrinológica.

\section{COMORBILIDADES}

\section{Alteraciones endocrinológicas}

El acné anormalmente grave, o los signos de hiperandrogenismo o la falla terapéutica obligan a considerar alguna alteración endocrinológica como: ${ }^{10}$ síndrome de ovario poliquístico, que es la causa más frecuente de hiperandrogenismo en mujeres. Este síndrome se caracteriza por irregularidades menstruales, hirsutismo, acné, quistes ováricos y grados variables de resistencia a la insulina.

El acné de inicio súbito asociado a virilización obliga a investigar un tumor suprarrenal u ovárico, síndrome de Cushing o hiperplasia suprarrenal congénita de inicio tardío. Los signos de virilización incluyen: voz profunda, disminución del tamaño de las mamas, clitoromegalia, alopecia, oligomenorrea e hirsutismo.

Los niños pre-púberes con acné y signos de exceso de andrógenos (olor apocrino de inicio temprano, vello púbico o axilar, crecimiento acelerado, edad ósea avanzada y maduración genital) también requieren evaluación endocrinológica. 


\section{Repercusiones en la calidad de vida}

El acné es una enfermedad visible, por lo que la morbilidad psicológica puede ser significativa considerando que en la adolescencia la imagen y autopercepción pueden determinar el comportamiento y las interacciones sociales. El grado de afectación no se relaciona, necesariamente, con la gravedad del acné por lo que debe considerarse la necesidad de una evaluación psicológica. Desestimar la repercusión que puede tener el acné en la calidad de vida de un adolescente puede generar efectos psicológicos que afecten etapas posteriores de la vida. ${ }^{11}$

\section{Diagnóstico diferencial}

Puesto que hay cuadros clínicos que simulan acné es necesario establecer el diagnóstico diferencial. Algunos padecimientos que pueden considerarse en el diagnóstico diferencial del acné son:

Dermatitis acneiforme. Aparece a cualquier edad, como una erupción monomorfa de pápulas o pápulo-pústulas más frecuentes en el tronco. No hay comedones. La causa más frecuente son los medicamentos, sobre todo los listados en el Cuadro 1.

Cuadro 1. Principales medicamentos relacionados con dermatitis acneiforme

Hormonas esteroides: glucocorticoides, andrógenos, corticotropina

\section{Anticonvulsivantes: fenitoína}

Halógenos: bromuros, fluoruros, yoduros (algas, sal, amiodarona y medios de radiocontraste), litio

Inhibidores del receptor del factor de crecimiento epidérmico: cetuximab, panitumumab, necitumumab, pertuzumab

Inmunosupresores: ciclosporina, azatioprina

\section{Tiourea}

Vitaminas $\mathrm{B}_{2}, \mathrm{~B}_{6}$ y $\mathrm{B}_{12}$

Isoniacida
Rosácea. Se caracteriza por eritema, telangiectasias y pápulas o pústulas en la región central de la cara, en ausencia de comedones.

Dermatitis perioral. Se caracteriza por pápulas pequeñas, eritematosas, aisladas o agrupadas. Puede aparecer a cualquier edad. La distribución periorificial, ausencia de comedones y el antecedente de consumo de esteroides inhalados son diagnósticos.

Foliculitis. Se caracteriza por micropústulas perifoliculares en cualquier sitio. No hay comedones ni pápulas.

Queratosis pilaris. Aparece como pápulas milimétricas blanquecinas foliculares. Son ásperas al tacto y pueden o no presentar eritema. En niños, la afectación facial es frecuente, además en los brazos y muslos. A menudo se confunde con acné, particularmente por los familiares. No hay comedones.

\section{TRATAMIENTO}

La mayor parte de las guías de tratamiento del acné se basan en opiniones de expertos. Los principios generales de tratamiento del acné son fundamentales para el mejor control. ${ }^{12}$

El tratamiento se dirige a las lesiones predominantes, debe reducirse al mínimo de medicamentos necesarios para no modificar las actividades del adolescente. El interés que el adolescente tenga en su enfermedad es determinante para el apego al tratamiento, porque es el factor principal que determina la falla de éste.

La explicación amplia de la naturaleza del acné al adolescente y a sus padres es tan importante como los medicamentos que debe consumir o aplicar. Debe incluir el concepto de cronicidad del acné y el tiempo de espera para conseguir resultados (4 a 8 semanas), sin omitir los posibles efectos secundarios. 
Los objetivos del tratamiento incluyen: disminuir la producción de sebo, prevenir la formación de comedones, suprimir $P$. acnes, disminuir las lesiones inflamatorias y prevenir las cicatrices.

La Figura 6 muestra un algoritmo que puede ayudar al médico de primer contacto a la toma de decisiones en un adolescente con acné juvenil. ${ }^{13}$

De acuerdo con Eichenfield y su grupo ${ }^{10}$ y con la experiencia de los autores el tratamiento recomendado es en términos generales:

\section{Acné no inflamatorio}

Comedónico. Lavado de la cara dos veces al día y evitar el uso de productos comedogénicos suele ser suficiente cuando la manifestación del acné es piel oleosa y algunos comedones.

\section{Acné inflamatorio}

Leve. Además de lo mencionado agregar peróxido de benzoílo, es efectivo como monoterapia y seguro. Tiene efecto comedolítico y antiinflamatorio además de su acción contra $P$. acnes, que se

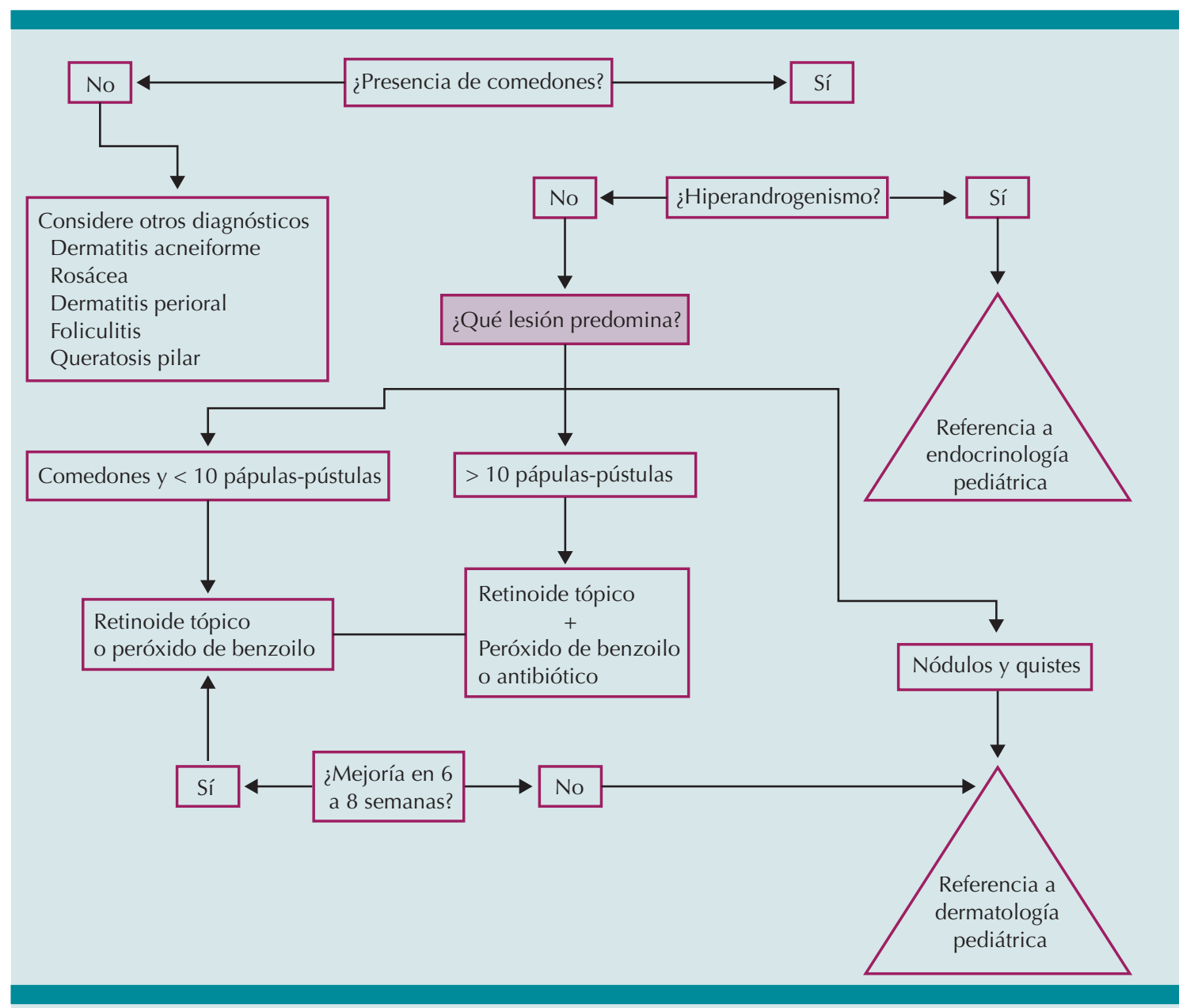

Figura 6. Algoritmo de tratamiento del paciente con acné juvenil. 
mantiene sin desarrollar resistencia bacteriana. Los retinoides tópicos son otra opción de monoterapia, son efectivos y seguros, su acción en el proceso de queratinización alterado previene la formación de comedones. El vehículo y la concentración del peróxido de benzoílo y de los retinoides tópicos permiten hacer cambios que mantienen su efectividad.

Moderado. Lavarse la cara dos veces al día y evitar el uso de productos comedogénicos. La estrategia inicial puede ser la combinación de peróxido de benzoílo (por la mañana) con un retinoide tópico (por la noche). Otra estrategia es la combinación de un retinoide tópico con antibiótico tópico (clindamicina o eritromicina), que son bien tolerados y no deben indicarse como monoterapia por el riesgo de resistencia bacteriana. Los antibióticos sistémicos (sobre todo tetraciclinas de primera y segunda generación) deben reservarse para los casos con poca reacción al tratamiento tópico o con lesiones en el tronco. La reacción se evalúa a las 6 a 8 semanas y la duración debe ser de 3 a 4 meses. El tratamiento tópico con peróxido de benzoílo o el retinoide tópico debe mantenerse. ${ }^{14}$ La prescripción de un retinoide sistémico (isotretinoína) está indicada en casos de difícil control o con falla al tratamiento.

Grave. Los pacientes con acné grave requieren tratamiento sistémico.

En términos generales se recomienda que el tratamiento sistémico del acné lo haga el especialista. La experiencia del pediatra en el tratamiento del acné debe ser el punto de inflexión para derivar al paciente con el dermatólogo pediatra.

\section{REFERENCIAS}

1. Vos T, Flaxman AD, Naghavi M, Lozano R, Michaud C, Ezzati $\mathrm{M}$, et al. Years lived with disability (YLDs) for 1160 sequelae of 289 diseases and injuries 1990-2010: a systematic analysis for the Global Burden of Disease Study 2010. Lancet.2012;380:2163-96.

2. Bhate K, Williams HC. Epidemiology of acne vulgaris. Br J Dermatol 2013; 168:474-85.

3. Santamaría GV, Valdés WRL. Acné juvenil inflamatorio. Evaluación de la calidad de vida con la encuesta SF-36. Rev Cent Dermatol Pascua. 2007;16:7-13.

4. Ruiz-Maldonado R, Tamayo-Sánchez L, Velázquez E. Epidemiología de las enfermedades de la piel en diez mil pacientes en edad pediátrica. Bol Med Hosp Infant. 1977; 34:137-161.

5. Del Pozo-Magaña BR, Lazo-Langner A, Gutiérrez-Castrellón P, Ruiz-Maldonado R. Common dermatoses in children referred to a specialized pediatric dermatology service in Mexico: A comparative study between two decades. ISRN Dermatol 2012; Article ID 351603, 5 pages. Doi:10.5402/2012/351603.

6. Ghodsi SZ, Orawa H, Zouboulis CC. Prevalence, severity, and severity risk factors of acne in high school pupils: a community-based study. J Invest Dermatol. 2009;129:2136-41.

7. Di Landro A, Cazzaniga S, Parazzini F, Ingordo V, Cusano F, Atzori $L$, et al. Family history, body mass index, selected dietary factors, menstrual history, and risk of moderate to severe acne in adolescents and young adults. J Am Acad Dermatol. 2012; 67:1129-1135.

8. Ulvestad M, Bjertness E, Dalgard F, Halvorsen JA. Acne and dairy products in adolescence: results from a Norwegian longitudinal study. J Eur Acad Dermatol Venereol. 2017;31:530-535.

9. Jović A, Marinović B, Kostović K, Čeović R, Basta-Juzbašić A, Bukvić Mokos Z. The Impact of pyschological stress on acne. Acta Dermatovenerol Croat. 2017;25:1133-141.

10. Echenfield LF, Krakowski AC, Piggott C, Del Rosso J, Baldwin $\mathrm{H}$, Fallon $\mathrm{S}$, et al. Evidence-based recommendations for the diagnosis and treatment of pediatric acne. Pediatrics. 2013;131: S163-S168.

11. Nguyen CM, Koo J, Cordoro KM. Psychodermatologic effects of atopic dermatitis and acne: A review on self-esteem and identity. Pediatr Dermatol. 2016; 33:129-135.

12. Zaenglein AL, Pathy AL, Schlosser BJ, Alikhan A, Baldwin HE, Berson DS, et al. Guidelines of care for the management of acne vulgaris. J Am Acad Dermatol. 2016;74:945-73.

13. Maza-Ramos G, Durán McKinster C, Liquidano-Pérez E. Manejo del acné. En: Asociación Mexicana de Pediatría, AC; Saltigeral-Simental P, Pinacho-Velazquez JL, coordinadores. PROPED Programa de Actualización en Pediatría; Ciclo 1. Ciudad de México: Artmed Panamericana, 2017;147-67.

14. Thiboutot $D M$, Dréno $B, A$ banmi A, Alexis AF, Araviiskaia $\mathrm{E}$, Barona $\mathrm{Cl}$, et al. Practical management of acne for clinicians: An International Consensus from the Global Alliance to Improve Outcomes in Acne. J Am Acad Dermatol. 2018;78:S1-S23. 